\title{
The Effect of Breast Size and Density in Turkish Women on Radiation Dose in Full-Field Digital Mammography
}

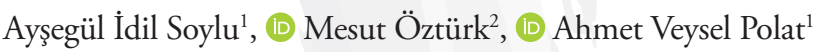 \\ ${ }^{1}$ Department of Radiology, Ondokuz Mayıs University, Faculty of Medicine, Samsun, Turkey \\ ${ }^{2}$ Department of Radiology, Samsun Gazi State Hospital, Samsun, Turkey
}

\begin{abstract}
Objective: The purpose of this study was to look into the relationship between breast size and mammographic breast density in women and breast radiation dose on full-field digital mammography (FFDM), as well as the factors that influence radiation dose.

Materials and Methods: The study included a total of 2,060 FFDM images from 515 consecutive participants. The participants were divided into two groups: those exposed to high doses $(>3 \mathrm{mGy})$ and those exposed to low doses $(<3 \mathrm{mGy})$. Moreover, the researchers analyzed the relationship between mean glandular dose (MGD) of the breast and patient age, compressed breast thickness, compression force, mammographic breast composition, and mammographic breast size.

Results: The mean mammographic breast volume was $936.2 \pm 425.2(114.5-3,018) \mathrm{mL}$, and the mean compressed breast tissue thickness was $56.75 \pm$ $10.44 \mathrm{~mm}$. Moreover, the mean MGD in the high-dose group was $3.51 \pm 0.48 \mathrm{mGy}$ and $1.92 \pm 0.56 \mathrm{mGy}$ in the low-dose group. The high-dose group had greater breast thickness, diameters, volume, compression pressure, and surgical rate. However, the high-dose group was younger and had less dense breasts. In multivariate logistic regression analysis, the most important predictors of dose determination were breast thickness [odds ratio (OR): 1.178, 95\% confidence interval (CI): $1.156-1.200, \mathrm{p}<0.001]$, history of previous surgery (OR: $2.210,95 \% \mathrm{CI}: 1.417-3.447, \mathrm{p}<0.001$ ), compression force (OR: $1.008,95 \% \mathrm{CI}$ : $1.004-1.013, \mathrm{p}<0.001$ ), and breast density (OR: $1.873,95 \%$ CI: 1.359-2.580, $\mathrm{p}<0.001$ ).

Conclusion: Women with larger breast volumes are subjected to higher doses of radiation. Therefore, breast-screening programs can be individualized to young women with larger breast volumes and women who have had breast-conserving surgery.
\end{abstract}

Keywords: Breast volume, mammography, radiation dose

Cite this article as: İdil Soylu A, Öztürk M, Polat AV. The Effect of Breast Size and Density in Turkish Women on Radiation Dose in Full-Field Digital Mammography. Eur J Breast Health 2021; 17(4): 315-321.

\section{Key Points}

- Breast cancer is the most common type of cancer in women worldwide.

- Breast tissue of women over the age of 40 is repeatedly exposed to ionizing radiation due to periodic screening programs.

- It is essential to know the factors affecting the amount of radiation dose to which breast tissue is exposed during routine screening programs and to use individualized screening programs in women to reduce radiation exposure.

\section{Introduction}

The link between radiation and cancer was discovered primarily through the victims of the Hiroshima and Nagasaki atomic bombings $(1,2)$. In order to reduce the risk of cancer caused by radiation, the frequency and dose of radiation exposure are kept as low as possible. The widespread use of radiation-based imaging modalities raises concerns about the risk of radiation-induced cancer.

Breast cancer is the most common type of cancer among women in Turkey, as it is in the rest of the world $(24.8 \%)(3,4)$. As a result, early detection of breast cancer is critical. Breast cancer screening programs aim to detect the disease at an early stage, before clinical symptoms appear. Mammography is the most commonly used imaging modality for breast cancer screening because of its high sensitivity and low cost (5-6). Moreover, breast cancer screening programs can reduce mortality by up to $30 \%$ (7). However, the breast tissue of women over the age of 40 is repeatedly exposed to ionizing radiation as part of a periodic screening program (8). Although it varies depending on the radiosensitivity of the tissue, it is known that the frequency of many cancers increases after radiation exposure (9). 
The purpose of this study was to look into the relationship between breast size and mammographic breast density in women and breast radiation dose on full-field digital mammography (FFDM), as well as the factors that influence radiation dose.

\section{Materials and Methods}

This retrospective study was approved by our institutional ethics committee for clinical trials. For a period of three months, consecutive mammographic images obtained in the mammography unit (Selenia, Hologic; Bedford, MA, USA) of our hospital were collected. Patients with unilateral mastectomy, mammography images with spot compression and magnification, mammograms taken during interventional procedures, patients with previously known large benign or malignant lesions, and male patient mammograms were excluded from the study. The study included all bilateral craniocaudal (CC) and mediolateral oblique (MLO) projection mammography images from eligible participants during the study period.

Breast composition was determined by two radiologists in consensus, using the Breast Imaging Reporting and Data System (BI-RADS) (10). Breasts in BI-RADS categories "a" and "b" were referred to as "nondense," while breasts in BI-RADS categories "c" and "d" were referred to as "dense." The mammographic size of the breast was determined using CC graphs and the measurement formula described by Kalbhen et al. (11) BV = 1/4 $\pi$ x Hcc x Wcc x Ccc (12). In this formula, the diameter of the breast parallel to the chest wall, the distance from the nipple to the chest wall, and the compressed breast thickness were all used (Figure 1). Patients who had previously undergone breast-conserving surgery were identified.

Data on the mean glandular dose (MGD) value, compressed breast thickness, and breast compression force were extracted from the Digital Imaging and Communications in Medicine (DICOM) labels of each image sent to our Picture Archiving and Communication System (PACS).

According to the Food and Drug Administration and the International Commission on Radiological Protection (ICRP), the safe limit for a single projection mammogram is $3 \mathrm{mGy}$ MGD. This dose value was accepted as a cutoff, and the participants were divided into two groups: those who received a high dose and those who received a low dose. Furthermore, the relationship between MGD and the age of the participants during mammography, breast diameters, compressed breast thickness, breast compression force, mammographic breast composition, and the mammographic breast volume were investigated using univariate and multivariate linear regression analyses.

\section{Definitions}

Total glandular dose: the total dose to which a breast is exposed during MLO and CC projection

MGD: the average dose of a breast exposed in MLO and CC projections.

\section{Statistical analysis}

SPSS 15.0 for Windows (IBM Inc., Armonk, NY, USA) was used determine whether the data distribution was normal. The student's t-test was used to compare data with a normal distribution. Linear regression analysis was also used to test the data's predictive effect on MGD. Furthermore, the forward elimination model was preferred for variable elimination. Continuous data were expressed as mean \pm standard deviation, and categorical data as percentages. Statistical significance was indicated by $\mathrm{p}<0.05$.

\section{Results}

A total of 2,060 images from 515 consecutive patients who had routine $\mathrm{CC}$ and MLO investigations were included in the study. The mean age of the patients was $55.9 \pm 8.8$ years. The mean mammographic volume of the breast per person was $936.2 \pm 425.2$ (114.5-3,018) $\mathrm{mL}$. In addition, the mean compressed breast tissue thickness was $56.75 \pm 10.44 \mathrm{~mm}$, and the mean compression force was $127.13 \pm$ $30.89 \mathrm{~N}$. When the patients were classified based on mammographic breast composition, 657 breasts (63.8\%) were classified as "nondense," while 373 breasts (36.2\%) were classified as "dense" (Figure 2). A total of 78 breasts $(7.6 \%)$ had a history of breast-conserving surgery. The mean MGD per image for CC images was $1.75 \pm 0.64 \mathrm{mGy}$ and 2.61 $\pm 0.71 \mathrm{mGy}$ for MLO images. For a single image, the mean MGD was $2.18 \pm 0.80 \mathrm{mGy}$. For a single breast, the total dose from twoprojection mammograms was $4.36 \pm 1.2 \mathrm{mGy}$. The mean MGD in the "nondense" and "dense" groups, $2.22 \pm 0.82$ and $2.10 \pm 0.76 \mathrm{mGy}$

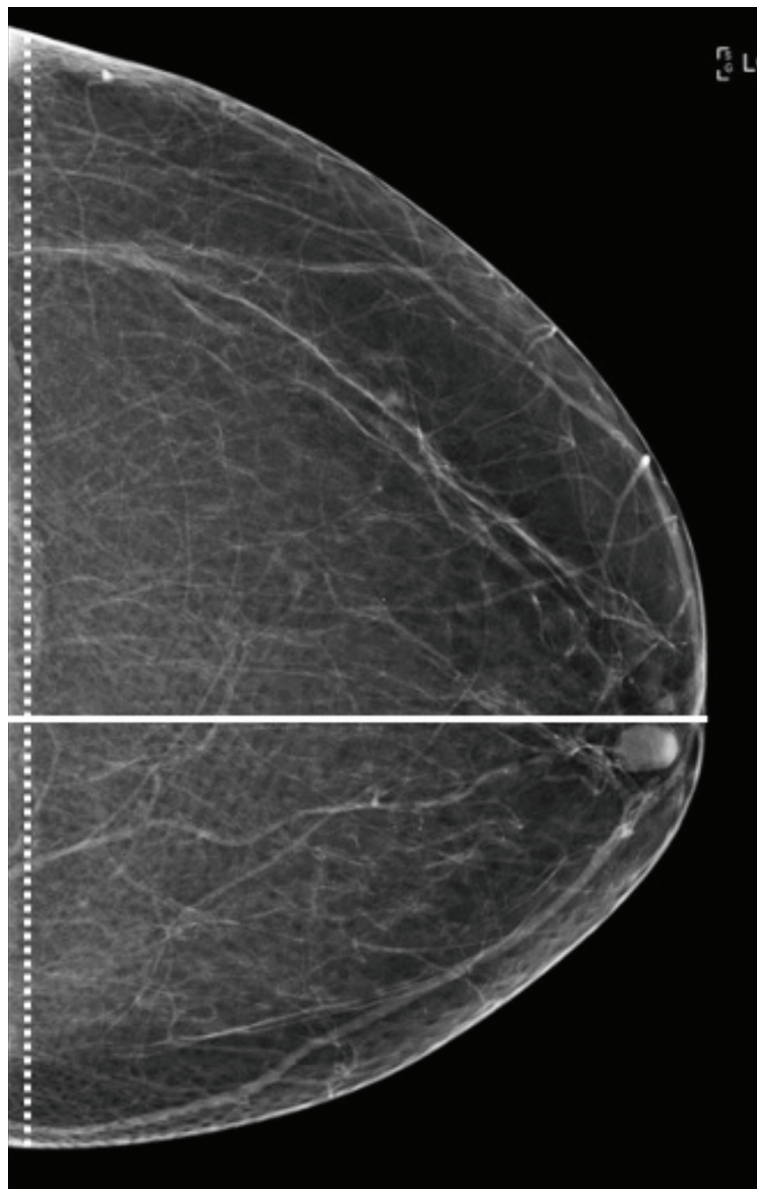

Figure 1. In craniocaudal projection, the following measurements were used to calculate breast volume: posterior-anterior height (dashed line), lateral-medial width (straight line), and breast thickness 
respectively, was significantly different $(\mathrm{p}=0.006)$, respectively. The volume of the breasts in the "dense" group was significantly lower than the volume of the breasts in the "nondense" group $(689.5 \pm 322.7$ vs $1,076.3 \pm 412.5, \mathrm{p}<0.001)$. In patients who had previously undergone breast surgery, the surgical side had higher MGD values $(2.63 \pm 0.99$ vs $2.15 \pm 0.77, \mathrm{p}<0.001)$ (Table 1$)$.

In $16.3 \%$ of the images, the radiation dose to which the breast tissue was exposed was greater than $3 \mathrm{mGy}$. The mean MGD in the highdose group was $3.51 \pm 0.48$ and $1.92 \pm 0.56$ in the low-dose group $(\mathrm{p}<0.001)$. The high-dose group had greater breast thickness, diameters, and volume, compression pressure, and surgical rate. However, patients in the high-dose group were younger and had lower breast density (Table 1).

In univariate logistic regression analysis, age and breast density were found to be negatively correlated with high MGD, whereas breast thickness, breast compression force, and surgical history were found to be positively correlated. On the other hand, in multivariate logistic regression analysis, the best model for predicting high MGD included breast thickness [odds ratio: (OR): 1.178, 95\% confidence interval (CI): 1.156-1.200, $\mathrm{p}<0.001]$, previous surgery history (OR: 2.210, 95\% CI: $1.417-3.447, \mathrm{p}<0.001$ ), compression force (OR: 1.008, 95\% CI: $1.004-1.013, \mathrm{p}<0.001$ ), and breast density (OR: 1.873,
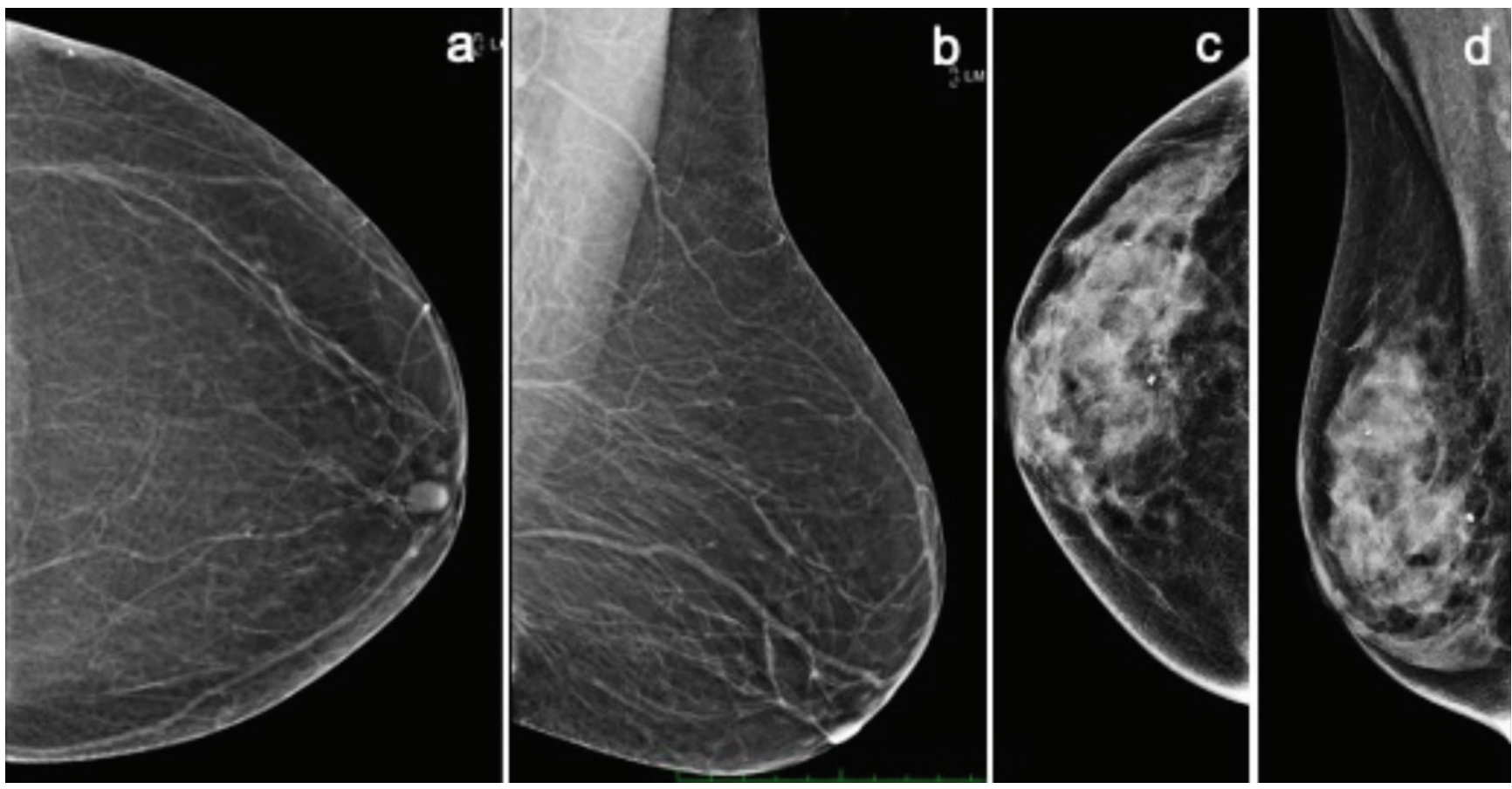

Figure 2. A 68-year-old woman with large breasts and a "nondense" breast composition. The average MGD per view was 1.19 mGy (a, b) a 46-year-woman with "dense" breast composition and small breasts. The average MGD per view was $2.87 \mathrm{mGy}(\mathbf{c}, \mathbf{d})$

MGD: Mean glandular dose

Table 1. Baseline characteristics

\begin{tabular}{|c|c|c|c|c|}
\hline & $\begin{array}{l}\text { All images } \\
(n=2060)\end{array}$ & $\begin{array}{l}\text { Low dose } \\
(n=1725)\end{array}$ & $\begin{array}{l}\text { High dose } \\
(n=335)\end{array}$ & p-value \\
\hline Age, years $(n=515)$ & $55.92 \pm 8.78$ & $56.21 \pm 8.7$ & $54.45 \pm 8.6$ & 0.001 \\
\hline Breast thickness $(\mathrm{mm})(\mathrm{n}=1030)$ & $56.7 \pm 10.44$ & $54.7 \pm 9.7$ & $67.1 \pm 7.2$ & $<0.001$ \\
\hline Breast diameter $1(\mathrm{~mm})(n=1030)$ & $198.10 \pm 24.65$ & $195.4 \pm 24.3$ & $212.1 \pm 21.5$ & $<0.001$ \\
\hline Breast diameter $2(\mathrm{~mm})(n=1030)$ & $100.63 \pm 25.32$ & $98.5 \pm 25.1$ & $111.9 \pm 23.6$ & $<0.001$ \\
\hline Volume $(\mathrm{mL})(n=1030)$ & $936.23 \pm 425.24$ & $869.6 \pm 392.8$ & $1279.2 \pm 420.4$ & $<0.001$ \\
\hline Compression $(N)(n=2060)$ & $127.13 \pm 30.89$ & $126.3 \pm 30.1$ & $131.3 \pm 34.6$ & 0.015 \\
\hline Radiation dose, mGy $(n=2060)$ & $2.18 \pm 0.80$ & $1.92 \pm 0.56$ & $3.51 \pm 0.48$ & $<0.001$ \\
\hline Surgical history, n (\%) (n= 2060) & $156(7.6)$ & $103(6)$ & $53(15.8)$ & $<0.001$ \\
\hline Dense breast, $n(\%)$ ( $n=2060$ ) & $746(36.2)$ & $654(37.9)$ & $92(27.5)$ & $<0.001$ \\
\hline
\end{tabular}

Breast diameter 1 : the diameter of the breast parallel to the chest wall on CC projection; Breast diameter 2: the distance from the nipple to the chest wall on CC projection. $\mathrm{N}$ - Newton

n: Number 
95\% CI: $1.359-2.580, \mathrm{p}<0.001)$. The high-dose determination power of this model was $86 \%$. Interestingly, the power of breast thickness alone to detect high MGD was 85\% (OR: 1.168, 95\% CI: 1.148 $1.189, \mathrm{p}<0.001)$. In the receiver operating characteristic analysis, the sensitivity of the $60-\mathrm{mm}$ thickness to determine high dose was $79.7 \%$, while the specificity was $76.8 \%$ [area under the curve (AUC) $=0.862$ $\mathrm{p}<0.001]$ (Graph 1).

In univariate regression analysis, breast density was negatively correlated with MGD but positively correlated with MGD in multivariate regression analysis $(\mathrm{p}<0.001)$ (Table 2$)$.

\section{Discussion and Conclusion}

Mammography is the mostly widely used imaging modality used for breast cancer screening, but the most significant disadvantage of the examination is radiation exposure. The mean dose absorbed by all fibroglandular tissue in the breast is referred to as MGD. MGD is linked to an increased risk of radiation-induced breast cancer.

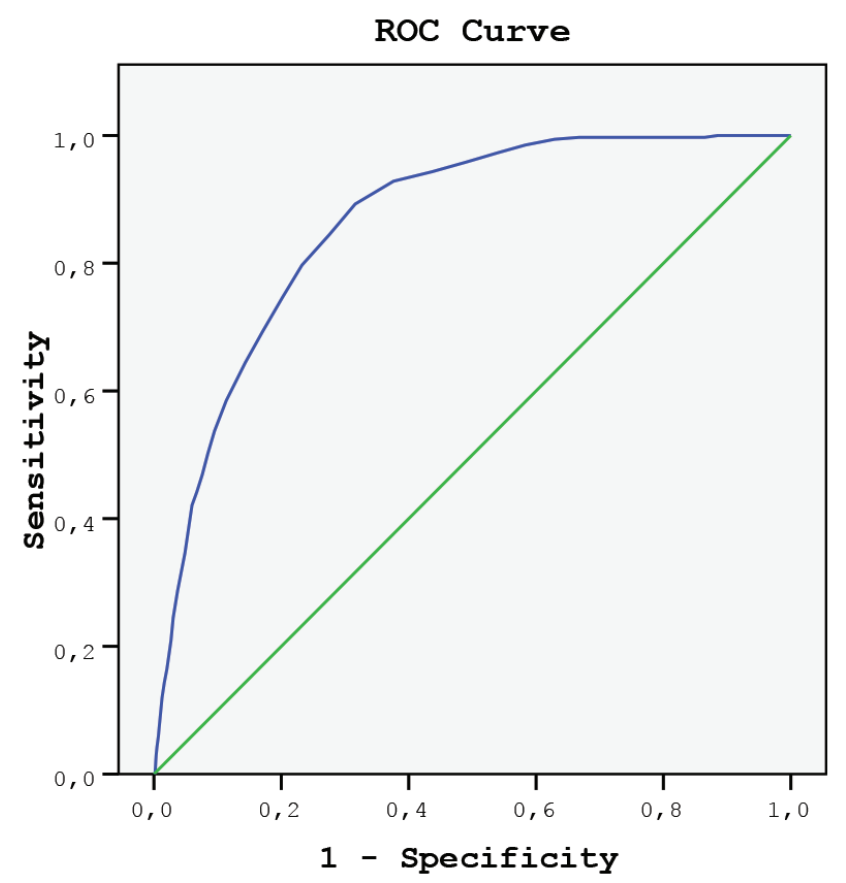

Graph 1. In the ROC analysis, the sensitivity of the 60-mm thickness to determine high dose was $79.7 \%$, while the specificity was $76.8 \%$ (AUC $=0.862, \mathrm{p}<0.001$ )

ROC: Receiver operating characteristic, AUC: Area under the curve
Therefore, radiation doses should be kept as low as possible in all imaging techniques using X-ray.

Hauge et al. (13) conducted a risk prediction study on 100,000 Norwegian women aged 50-69 years who were screened with mammography at 2-year intervals and calculated the risk of radiationinduced breast cancer as 10/100,000 for a dose of $2.5 \mathrm{mGy}$. Using the same parameters, the number of radiation-induced breast cancer deaths was calculated as $1 / 100,000$ (6). According to Warren et al. (14), the number of deaths caused by radiation-induced breast cancers was 150 times lower than the number of lives saved by screening. Although the risk of radiation-induced-cancer from mammography is extremely low, repeated radiation exposure has been linked to an increased risk of breast cancer (15).

Radiation dose is proportional to the size and density of the breast. In general, obese women with large, dense breasts and thick compressed breast tissue are exposed to higher radiation doses.

In our study, $25 \%$ of the participants were between the ages of 25 and 49, and a significant relationship was discovered between young age and high MGD. This could be explained by the dense breast pattern often found in younger women, which necessitates higher doses. On the other hand, since the radiosensitivity of breast tissue is negatively correlated with age, being young is associated with an increased risk of radiation-related cancer and death. As a result, careful radiation dose regulation is critical in young women undergoing mammography.

Breast screening programs employ standard CC and MLO projections for each breast. In our study, MGD per projection was $1.75 \pm 0.64$ mGy for CC images and $2.61 \pm 0.71 \mathrm{mGy}$ for MLO images, with a total MGD of $4.36 \pm 1.2 \mathrm{mGy}$ for a single breast. In a similar study on Saudi women, the MGD for single breasts was $1.02 \pm 0.2 \mathrm{mGy}$ (0.4-1.8) for CC projections and $1.1 \pm 0.3 \mathrm{mGy}(0.5-1.8)$ for MLO projections, for a total of $2.12 \mathrm{mGy}$ per breast (16). In a similar study on Korean women, Baek et al. (17) reported a total MGD for a single breast at two-projection mammograms of $3.62 \mathrm{mGy}$ and an average effective dose of $0.43 \mathrm{mSv}$. Considering the tissue weighting factor ( 0.12 for breast tissue) of the ICRP, the mean effective dose for a single breast in our study was calculated to be $0.52 \mathrm{mSv}$ (18). In the ACRIN-Digital Mammographic Imaging Screening Trial by Hendrick et al. (19), MGD was reported as $3.7 \mathrm{mGy}$ on twoprojection digital mammography. The MGD determined by Food and Drug Administration for a single projection in digital mammography

Table 2. Univariate and multivariate logistic regression analysis to determine high dose (>3 mGy)

\begin{tabular}{lcccccc} 
Predictor & Odds ratio & $\mathbf{9 5 \%} \mathbf{C l}$ & P-value & Odds ratio & $\mathbf{9 5 \%} \mathbf{C l}$ & P-value \\
\hline Age, (years) & 0.977 & $0.963-0.990$ & $<0.001$ & - & - \\
Compression, (N) & 1.005 & $1.001-1009$ & $<0.007$ & 1.008 & $1.004-1.013$ & $<0.001$ \\
Surgery, (Y/N) & 2.960 & $2.076-4.219$ & $<0.001$ & 2.210 & $1.417-3.447$ & $<0.001$ \\
Breast thickness, (mm) & 1.168 & $1.148-1.189$ & $<0.001$ & 1.178 & $1.156-1.200$ & $<0.001$ \\
Dense breast, (Y/N) & 0.620 & $0.479-0.803$ & $<0.001$ & 1.873 & $1.359-2.580$ & $<0.001$
\end{tabular}

Y/N: Yes or No; N: Newton; Cl: Confidence interval 
Soylu et al. The Effect of Breast Structural Factors

(standard breast thickness: $42 \mathrm{~mm}, 50 \%$ fibroglandular tissue, $50 \%$ adipose tissue) should not exceed $3 \mathrm{mGy}$ (20). The ICRP recommends a dose limit of $3 \mathrm{mGy}$ for each projection (18). In the European protocol, a reference dose limit of $2.5 \mathrm{mGy}$ per image is recommended for a standard breast of 53-mm thickness (21). In our study, the MGD of women was higher than the doses reported in other studies, but it was still within the allowed dose limits.

While the mean breast tissue volume in Western women is 551.95$774 \mathrm{~mL}$, Baek et al. (17) found that breast volume in Korean women ranged from 380.9 to $466.4 \mathrm{~mL}$. In our study, the mean breast tissue volume was calculated to be $936.2 \pm 425.2(114.5-3018) \mathrm{mL}$. Moreover, women in our study had larger breast volumes than both Asian and Western women. In terms of breast density, 36.9\%-51\% of Western women and $61.9 \%-86.4 \%$ of Korean women have a dense mammographic breast composition (22-25). In our study, the dense breast composition ratio in Turkish women was calculated to be $36.2 \%$, which was comparable to the lower end of the range for that of Western women.

Warren et al. (14) reported an MGD of 3 mGy for small breasts and a range of 5-10 mGy for large breasts. Further, Young and Oduko (26) studied the radiation dose received during the breast-screening program on 25,409 women living in the United Kingdom. According to their findings, $1.8 \%$ of the population has large breast tissue (breast thickness $>90 \mathrm{~mm}$ ), and women with large breasts have 1.7 times the radiation exposure compared to the general population (26). According to the regression analysis performed in our study, breast thickness was the most powerful parameter determining MGD level. Breast thickness increases as a result of increased breast volume. In our study, breast diameters in two axes, breast thickness, and breast volume were significantly different between women exposed to a low dose $(<3$ $\mathrm{mGy}$ ) and those exposed to a high dose ( $>3 \mathrm{mGy}$ ). Given that the women in our study had larger breast volume than women of other ethnicities, it is possible that the relatively high dose detected was due to the larger breast volume.

High MGD is associated with "dense" mammographic breast composition (27). When compared to European and North American women, Asian women have smaller but more dense breast patterns (28). In the study of Baek et al. (17), Korean women were found to be exposed to higher MGD due to their small but denser breast pattern. However, in our study, the nondense group had higher MGD values than the dense group. Furthermore, univariate regression analysis revealed a negative correlation between breast density and MGD. However, women with dense breast patterns had significantly smaller breast volume than the nondense group. Therefore, higher MGD in the nondense group of our study population was most likely associated with higher breast volume in these women. This is supported by the fact that when the volume parameter was disabled, the multivariate regression analysis revealed a significant association between breast density and increased MGD.

Mammographic compression reduces superposition and thickness of breast tissue while maintaining homogeneity, and it also decreases radiation exposure (29-32). However, pain is a significant problem of compression, especially in patients who have had breast surgery
(33). According to the Norwegian breast cancer screening program guidelines, the compression force should be between 108 and 177 $\mathrm{N}$. It has been reported that compressing the breast tissue after a certain point causes discomfort in the patient rather than a decrease in breast thickness (34). In our study, the mean breast compression force was $127.13 \pm 30.89 \mathrm{~N}$, and there was a negative relationship between compression force and MGD. This can be explained by a reduction in the required dose caused by a decrease in breast thickness as a result of increased compressive force. In a study evaluating the relationship between breast compression and MGD in Asian women by Lau et al. (35), the mean compression pressure was reported to be $122.2 \pm 34.5 \mathrm{~N}$, which was close to the value in our study.

Our results showed that patients with a history of breast-conserving surgery required a higher MGD. We believe this was due to increased tissue density, caused by postoperative edema, skin thickening, surgical scar tissue, and existing surgical clips $(36,37)$.

We had some limitations: it was a single-center study. As a result, multicenter studies are needed to evaluate more objectively. MGD reflects the dose delivered by the machine, not the dose received by the breast. Therefore, the dose to which the breast is exposed may be reduced.

In conclusion, although the risk of cancer from mammography is extremely low, dose optimization is critical due to the repeated radiation exposures during screening programs. Women with larger breast volumes are subjected to higher doses of radiation. Moreover, screening programs and radiation doses can be individualized to women who are young, have larger breast volume, and have had breast-conserving surgery.

Ethics Committee Approval: This study was approved by Ondokuz Mayıs University Faculty of Medicine (no: B.30.2.ODM.0.20.08/634, date: 02.08.2019).

Informed Consent: Retrospective study.

Peer-review: Externally peer-reviewed.

\section{Authorship Contributions}

Conception: A.İ.S., A.V.P.; Design: A.İ.S., A.V.P.; Data Collection and/ or Processing: A.İ.S., M.Ö., A.V.P.; Analysis and/or Interpretation: A.İ.S., M.Ö., A.V.P.; Literature Review: A.İ.S., A.V.P.; Writing: A.İ.S., A.V.P.; Critical Review: İ.S., A.V.P.

Conflict of Interest: No conflict of interest was declared by the authors.

Financial Disclosure: The authors declare that this study received no financial support.

\section{References}

1. National Research Council (US) Committee to Assess Health Risks from Exposure to Low Level of Ionizing Radiation. Health risks from exposure to low levels of ionizing radiation: BEIR VII phase 2. Washington: National Academies Press; 2006. p. 406. [Crossref]

2. Preston DL, Pierce DA, Shimizu Y, Cullings HM, Fujita S, Funamoto $S$, et al. Effect of recent changes in atomic bomb survivor dosimetry on 
cancer mortality risk estimates. Radiat Res 2004; 162: 377-389. (PMID: 15447045) [Crossref]

3. Turkey cancer statistics. T.C. Ministry of Health, Public Health Agency of Turkey, Ankara 2016. Available at: https://hsgm.saglik.gov.tr/tr/kanseristatistikleri/yillar/2016-yili-turkiye-kanser-i-statistikleri.html [Crossref]

4. Bray F, Ferlay J, Soerjomataram I, Siegel RL, Torre LA, Jemal A. Global cancer statistics 2018: GLOBOCAN estimates of incidence and mortality worldwide for 36 cancers in 185 countries. CA Cancer J Clin 2018; 68: 394-424. (PMID: 30207593) [Crossref]

5. Migowski A. [Early detection of breast cancer and the interpretation of results of survival studies]. Cien Saude Coletiva 2015; 20: 1309. (PMID: 25923642) [Crossref]

6. Funke M. [Diagnostic imaging of breast cancer: an update.] Radiologe 2016; 56: 921-938. (PMID: 27600118) [Crossref]

7. Lee CH, Dershaw DD, Kopans D, Evans P, Monsees B, Monticciolo D, et al. Breast cancer screening with imaging: recommendations from the Society of Breast Imaging and the ACR on the use of mammography, breast MRI, breast ultrasound, and other technologies for the detection of clinically occult breast cancer. J Am Coll Radiol 2010; 7: 18-27. (PMID: 20129267) [Crossref]

8. Law J, Faulkner K, Young KC. Risk factors for induction of breast cancer by X-rays and their implications for breast screening. Br J Radiol 2007; 80: 261-266. (PMID: 17038413) [Crossref]

9. Boice JD. Cancer following medical irradiation. Cancer 1981; 47: 10811090. (PMID: 7237365) [Crossref]

10. Radiology ACo. BI-RADS Mammography 2013-ACR BI-RADS Atlas, 5th ed. Reston, VA: American College of Radiology; 2013 [Crossref]

11. Kalbhen C, McGill J, Fendley P, Corrigan K, Angelats J. Mamographic determination of breast volume: comparing different methods.AJR Am J Roentgenol 1999; 173: 1643-1649. (PMID: 10584814) [Crossref]

12. Rostas JW, Bhutiani N, Crigger M, Crawford SMW, Hollenbach RB, Heidrich SR, et al. Calculation of breast volumes from mammogram: comparison of four separate equations relative to mastectomy specimen volumes. J Surg Oncol 2018; 117: 1848-1853. (PMID: 29790170) [Crossref]

13. Hauge IHR, Pedersen K, Olerud HM, Hole EO, Hofvind S. The risk of radiation-induced breast cancers due to biennial mammographic screening in women aged 50-69 years is minimal. Acta Radiol 2014; 55: 1174-1179. (PMID: 2431170) [Crossref]

14. Warren LM, Dance DR, Young KC. Radiation risk of breast screening in England with digital mammographyy Br. J. Radiol 2016; 89: 20150897 doi: 10.1259/bjr.20150897. (PMID: 27585843) [Crossref]

15. Mughal B, Muhammad N, Sharif M, Rehman A, Saba T. Removal of pectoral muscle based on topographic map and shape-shifting silhouette. BMC Cancer 2018; 18: 778. (PMID: 30068304) [Crossref]

16. Sulieman A, Serhan O, Al-Mohammed HI, Mahmoud MZ, Alkhorayef $\mathrm{M}$, Alonazi B, et al. Estimation of cancer risks during mammography procedure in Saudi Arabia. Saudi J Biol Sci 2019; 26: 1107-1111. [Crossref]

17. Baek JE, Kang BJ, Kim SH, Lee HS. Radiation dose affected by mammographic composition and breast size: first application of a radiation dose management system for full-field digital mammography in Korean women. World J Surg Oncol 2017; 15: 38 (PMID: 28153022) [Crossref]

18. International Commission on Radiological Protection. The 2007 Recommendations of the International Commission on Radiological Protection. ICRP publication 103. Ann ICRP 2007; 37: 1-332. (PMID: 18082557) [Crossref]
19. Hendrick RE, Pisano ED, Averbukh A, Moran C, Berns EA, Yaffe MJ, et al. Comparison of acquisition parameters and breast dose in digital mammography and screen-film mammography in the American College of Radiology Imaging Network digital mammographic imaging screening trial. AJR Am J Roentgenol 2010; 194: 362-369. (PMID: 20093597) [Crossref]

20. Food and Drug Administration Summary of Safety and Effectiveness. August, 2017 Available at: https://www.fda.gov/media/123081/download [Crossref]

21. European Commission. European protocol for the quality control of the physical and technical aspects of mammography screening. In: European guidelines for quality assurance in breast cancer screening and diagnosis. 4th ed. EUREF Luxembourg: European Commission; 2006. [Crossref]

22. Gweon HM, Youk JH, Kim J-A, Son EJ. Radiologist assessment of breast density by BI-RADS categories versus fully automated volumetric assessment. Am J Roentgenol 2013; 201: 692-697. (PMID: 23971465) [Crossref]

23. Brandt K, Scott C, Ma L, Mahmoudzadeh A, Jensen M, Whaley D, et al. Comparison of clinical and automated breast density measurements: implications for risk prediction and supplemental screening. Radiology 2016; 279: 710-719. (PMID: 26694052) [Crossref]

24. Van der Waal D, den Heeten G, Pijnappel R, Schuur K, Timmers JMH, Verbeek ALM, et al. Comparing visually assessed BI-RADS breast density and automated volumetric breast density software: a cross-sectional study in a breast cancer screening setting. PLoS One 2015; 10: e0136667. (PMID: 26335569) [Crossref]

25. Ko SY, Kim EK, Kim MJ, Moon HJ. Mammographic density estimation with automated volumetric breast density measurement. Korean J Radiol 2014; 15: 313-321. (PMID: 24843235) [Crossref]

26. Young KC, Oduko JM. Radiation doses received in the United Kingdom breast screening programme in 2010 to 2012. Br J Radiol 2016; 89: 20150831. (PMID: 26654386) [Crossref]

27. Ozdemir A. Clinical evaluation of breast dose and the factors affecting breast dose in screen-film mammography. Diagn Interv Radiol 2007; 13: 134-139. (PMID: 17846987) [Crossref]

28. Geeraertt N, Klausz R, Muller S, Bloch I, Bosmans H. Breast characteristics $\&$ dosimetric data in X-ray mammography A Large Sample Worldwide Survey IAEA 2012. International Conference on Radiation Protection in Medicine, Bonn, Germany. CN-192 (7) 2012. p. 15 [Crossref]

29. Branderhorst W, de Groot JE, Highnam R, Chan A, Bohm-Velez M, Broeders MJ, et al. Mammographic compression-a need for mechanical standardization. Eur J Radiol 2015; 84: 596-602. (PMID: 25596915) [Crossref]

30. Yaffe MJ. AAPM tutorial. Physics of mammography: image recording process. Radiographics 1990; 10: 341-363. (PMID: 2183301) [Crossref]

31. de Groot JE, Broeders MJ, Branderhorst W, den Heeten GJ, Grimbergen CA. A novel approach to mammographic breast compression: improved standardization and reduced discomfort by controlling pressure instead of force. Med Phys 2013; 40: 081901. (PMID: 23927315) [Crossref]

32. Chen B, Wang Y, Sun X, Guo W, Zhao M, Cui G, et al. Analysis of patient dose in full field digital mammography. Eur J Radiol 2012; 81: 868-872. (PMID: 21397423) [Crossref]

33. Broeders MJ, Ten Voorde M, Veldkamp WJ, van Engen RE, van Landsveld-Verhoeven C, Jong-Gunneman MN, et al. Comparison of a flexible versus a rigid breast compression paddle: pain experience, projected breast area, radiation dose and technical image quality. Eur Radiol 2015; 25: 821-829. (PMID: 25504427) [Crossref] 


\section{Soylu et al. The Effect of Breast Structural Factors}

34. Waade GG, Moshina N, Sebuødegård S, Hogg P, Hofvind S. Compression forces used in the Norwegian Breast Cancer Screening Program. Br J Radiol 2017; 90: 20160770. (PMID: 28102696) [Crossref]

35. Lau S, Abdul Aziz YF, Ng KH. Mammographic compression in Asian women. PLoS One 2017; 12: e0175781. (PMID: 28419125) [Crossref]

36. Couto LS, Freitas-Junior R, Correa RS, Peixoto JE, Almeida CD, Rodrigues DCN, et al. Mean glandular dose in digital mamography in women with breast implants. J Radiol Prot 2019; 39: 498-510. (PMID: 30812019) [Crossref]

37. Lewis JL, Tartter PI. The value of mammography within 1 year of conservative surgery for breast cancer. Ann Surg Oncol 2012; 19: 32183222. (PMID: 22766990) [Crossref] 